\title{
Supportive care: men's expectations who undergoing in vitro fertilization treatment
}

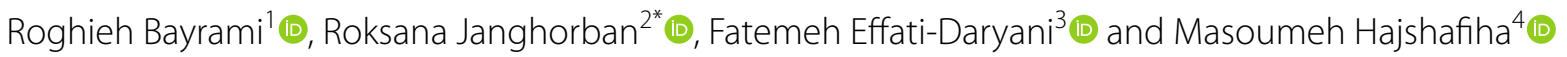

\begin{abstract}
Objective: Infertile couples perceive some needs and expectations during treatment. Most studies have focused on infertile women's needs. The study was done to explore the expectations of men who undergoing in in vitro fertilization (IVF) treatment. Participants were men whose wives undergo IVF treatment in the IVF clinic of Shahid Motahhri hospital in Urmia. Purposive sampling was performed and data collection was done through in-depth semi-structured interviews until data saturation.

Results: "Supportive care" was emerged as the main theme consisted of two categories. The first category was "to be treated with attention in healthcare setting" which included three subcategories: Receiving couple based care, establishing counseling centers, and continuous care. The second category was "to be welcomed in the society" which included two subcategories: Financial support from community and close family, and changing community views about IVF treatment. Expectations of men undergoing IVF focuses on supportive care. They seek to receive the kind of care from health care setting and society. A deep understanding of the needs could help practitioners to consider men's expectations, and assist policy makers and researchers to design and implement interventions and programs in infertility clinics which enhance the partnership of infertile men and fulfill their expectations.
\end{abstract}

Keywords: Counseling, Fertilization in vitro, Infertility, Qualitative research, Reproduction

\section{Introduction}

Infertility is a life crisis and infertile couples perceive some needs and expectations during treatment [1-3]. Global pattern of infertility showed that absolute number of infertile couples has increased and over 52 million couples in 2010 [4]. Infertility rate trend has been increased from $2.8 \%$ in 2001 to $24.9 \%$ in 2010 in Iranian couples [5]. Therefore, infertility treatment has become increasingly and women are the center of most infertility treatments in the increased rate [6]. Remarkable studies showed that women undergoing in vitro fertilization (IVF) experienced anxiety, depressive symptoms, and poor quality of life $[7,8]$. In spite of gender differences

\footnotetext{
*Correspondence: janghorban@sums.ac.ir; roksana542002@yahoo.com 2 Department of Midwifery, School of Nursing and Midwifery, Community Based Psychiatric Care Research Center, Shiraz University of Medical Sciences, 7193613119 Shiraz, Iran

Full list of author information is available at the end of the article
}

in psychological and emotional reactions during diagnosis and treatment of infertility, it affects men in various situations $[2,9]$. They could be as a partner of an infertile woman or they could encounter with their own infertility or they could experience unexplained infertility as an infertile couple $[10,11]$.

The psychological symptoms are increased during diagnosis and treatment of infertility or even the transition to fatherhood in men with infertility history $[12,13]$. Since infertility is a multifaceted problem, its effects could not limit to emotional consequences [14]. To our knowledge, most studies have focused on male psychological wellbeing and needs in infertility but less is known about the multi-dimensional needs of infertile men seeking assisted reproduction treatment (ART) and their thoughts and experiences regarding their fertility care [15-17]. There is also evidence that men, unlike women, rarely express their problems and needs in the health service $[18,19]$. 
Considering to existing gap, the qualitative research was done to explore the expectations of men who undergoing in IVF treatment.

\section{Main text \\ Methods}

A qualitative study was selected for this study. This approach is appropriate when previous studies have not focused on understudied subject and deep descriptions of a phenomenon are desired [20]. The study was conducted in the IVF clinic of Shahid Motahhri educational hospital in Urmia, which is referral center for infertility couples assessment in West Azerbaijan Province of Iran.

\section{Inclusion criteria}

Men who experienced IVF treatment for their wives were included in this study. 28 individual interviews with 26 participants (19 men, 2 gynecologists, 3 wives, 2 midwives) were performed. Inclusion criteria of men's participants were Iranian, speaking in Persian language, fertile or infertile men was monogamous whose wives undergoing IVF with own sperm and ovum, not having step-child and the tendency to share their experiences. Exclusion criteria were having history of divorce and remarriage, and gamete donation.

\section{The data collection tools}

Data were collected through in-depth, semi-structured, face-to-face interviews using interview guide which has previously been published [21]. Interviews lasted 45-100 min. Interviews were conducted in a private room in the hospital to assure their confidentiality and comfort. A second round of interviews was also conducted for two participants. The interviews were voice recorded and immediately transcribed verbatim.

\section{Setting and recruitment}

In the present study, purposive sampling was performed. In order to increase exploring different opinions in this group, maximum diversity of men's characteristics including age, educational level, employment, cause and duration of infertility was considered.

\section{Analysis}

Data were analyzed using Graneheim and Lundman qualitative content analysis method [22]. Similar codes were classified into subcategories and then were made into a category. Meanings was extracted in categories emerged a comprehensive meaning as the main theme. Data analysis was conducted by MAXqda software version 10 . The study was approved by the Research Ethics Committee of Urmia University of Medical Sciences (IR.UMSU. REC.1396.127). Written informed consent was signed by all participants before each interview. Confidentiality was ensured at all stages of the research. The trustworthiness of the research was considered according to Lincoln and Guba's measures [23].

\section{Results}

"Supportive care" was the men's expectation who their wives undergoing IVF treatment that emerged as the main theme. This theme consisted of two categories: to be treated with attention in healthcare setting with three subcategories, and to be welcomed in the society with two subcategories (Table 1).

\section{To be treated with attention in healthcare setting}

Receiving couple based care Men needed "receiving couple- based care" in all procedures, treatments and intervention. Men expressed that they expected involvement in the treatment both as a man and as a couple. They did not wish only to be place on the side-line. One man commented, "They should allow me to decide on whether to planned sexual intercourse or to start IVF process". [Man 12,30 years old, 5 years infertility, female cause].

Men did not have enough participation in planning for pregnancy. One participant stated: "Unfortunately, in our society only women are considered in infertility care and men is neglected or ignored". [Man 2, 31 years old, 4 years infertility, female cause].

One of the midwives stated: "The health of couples undergoing IVF treatment affects the child's health. We do not pay attention to the issue, and we believe that only mothers should be cared for". [Female midwife, 32 years old, 8 years of work experience].

Table 1 Subcategories, categories, and theme emerged from the study

\begin{tabular}{ll}
\hline Subcategory & Category \\
\hline $\begin{array}{l}\text { Receiving couple based care } \\
\text { Establishing counseling centers }\end{array}$ & To be treated with attention in healthcare setting \\
$\begin{array}{l}\text { Continuous care } \\
\text { Financial support from community and close family } \\
\text { Changing community views about IVF treatment }\end{array}$ & To be welcomed in the society \\
\hline
\end{tabular}


Establishing counseling centers Participants voiced a variety of preferences for receiving support, and counseling from IVF clinic. They believed that couples' involvement in counseling sessions is essential. Participants pointed out that there is nowhere to address their physical, sexual and psychological concerns before and after the IVF treatment. One gynecologist said:

"Unfortunately women rarely revisit us for their sexual concerns after the IVF but I think the most suitable person to help them is a sex therapist in a consultation center. Additionally their spouses' needs should be considered alongside them". [Female gynecologist, 52 years old, 20 years of work experience].

Another participant implied, "The doctors or other providers at the IVF clinic do not provide the psychological counseling and support that we need. I hope that there is a psychological counseling center that can provide us support". [Man 9, 32 years old, 7 years infertility, female cause].

Continuous care Some participants wanted continuous care. They liked to doctors and health care providers work within team. One participant said, "To maintain a care chain it would help if doctors would discuss treatment possibilities together, adjust one order and write this down in the patients' record and then he/she implements the treatment". [Man 18, 34 years old, 5 years infertility, female cause].

The majority of men believed that care from preconception period until IVF treatment and after that time should be provided by a certain team. On the other hand paying attention to the transition of patients and documents between clinics in different cities is important because it interrupts continuous care. One of midwives said, "Cares must be taken in a team from before to after of IVF. It might be necessary patients can be followedup". [Female midwife, 45 years old, 15 years of work experience].

\section{To be welcomed in the society}

Financial support from community and close family Difficulty in finding drugs, long distance to the IVF treatment center and financial problems were some of the difficulties that many participants encountered with it.

One of participants said, "Only I am employed and I lose all income on the days that we attended clinics". [Man 13, 33 years old, 6 years infertility, female cause]. Another man implied, "We had borrowed a loan from the bank and spent it for the treatment". [Man 17, 39 years old, 7 years infertility, female cause].
Most of participants came from other cities. The participants expected that their near family and friends would be support to assist them. One participant said, "The IVF treatment center is in Urmia. We had to stay in the hotel at night. We have near family and friends in Urmia and we expect to support and hold our hands in this city". [Man 5, 36 years old, 9 years infertility, male cause].

Majority of participants believed that the insurance services are needed to help more. One of the participants said, "Buying the drugs was difficult and the insurance services did not help us". [Man 8, 32 years old, 4 years infertility, female cause].

Changing community views about IVF treatment Some participants wanted the community's positive attitude towards male infertility and IVF treatment. Majority of men felt a sense of stigma while engaging in treatments which in conflict with their masculine sense. One man said: "I am afraid that around people think I cannot produce sperm. This is a taboo in our community and it was a reason that I wouldn't want to tell someone about IVF treatment". [Man 8, 30 years old, 6 years infertility, female cause].

\section{Discussion}

Iranian men who their wives undergoing IVF treatment need to "supportive care" as the main expectation. Men expected to receive couple- based care and did not want only to be placed on the side-line. The present findings agree with the results obtained in Arya and Dibb study. They showed that men reported feeling dismissed from the treatment process and their contribution was ignored [24]. In the response of the necessity of the couple-based care, Ying et al. developed the partnership and coping enhancement for couples undergoing IVF treatment [8].

Participants expected to access to counseling center. They sought to take advice from professionals about their sexual concerns and psychological distress. The need was not met due to lack of enough time of medical professional during treatment process. The findings confirmed by Roudsari and Allan which argued professionals must implement holistic approach in infertile couple counseling for fulfillment of their multifaceted needs in psychological, social and cultural issues [14]. Attention to psychological and emotional needs is very essential especially in Iranian infertile couples because prevalence of depression in these couples was high [25]. Besides, previous studies showed that men's depressive symptoms increase in male factor infertility and more attention to their emotional counseling is necessary [26, 27]. Although the cause of infertility in half of participants in the current research was different from the cited studies, 
their remarks showed that establishing counseling center can meet their various needs.

Continuous care was the other men's expectations. They preferred a certain team was responsible of their treatment process. The present findings agree with the results of previous studies showed that continuity is a dimension of patient centered care which was considered very little and were related to higher tolerability of treatment and lower depression [28-30].

Participants needed to financial support from community and close family. They endure many problems due to experience IVF failure, repeated IVF cycles, and lack of insurance coverage of infertility treatment. These financial problems increased when they have to go to another city for treatment. The present findings concur with the results of Hossein Rashidi et al. study that $61 \%$ of couples had economic difficulties and inaccessibility of insurance coverage for infertility services was the most important cause of treatment discontinuation [31]. The result was confirmed by a study showed that patients' out- ofpocket payment for infertility treatment is "considerable expenditure" in developing countries [32].

Men expected the community's positive attitude towards infertility. They did not tell about their infertility, treatment process to close family and other friends due to fear of stigma around the infertility in the society. They felt a deficit which was in conflict with the definition of their masculinity. Some studies showed that Iranian infertile couples experience the stigma and tendency to concealing infertility and doing IVF as a treatment method from their relatives [33, 34]. The results of Arya and Dibb's study agree with the current study that showed that perceived stigma and unsupported family is men's experiences during infertility treatment [24]. A study showed that decision to secrecy intensifies in donor insemination, egg donation and surrogacy [35]. Although, IVF was done using couples' sperms and ovums, in the current study, but results showed that men was stigmatized and had a tendency to hide. In conclusion, this study showed that expectations of men undergoing IVF focuses on supportive care. They seek to receive the kind of care from health care setting and society. A deep understanding of the needs could help policy makers and health professionals to design and implement interventions which enhance the partnership of infertile men and fulfill their expectations.

\section{Limitations}

The present findings are also limited by the issue that only male or female factor were found as a cause of participants' infertility. Unexplained cause of infertility may influence men's expectation.
Abbreviations

IVF: In vitro fertilization; MAXQDA: MAX Qualitative Data Analysis; ART: Assisted reproductive technology.

\section{Acknowledgements}

This study was financially supported by Urmia University of Medical Sciences, Urmia, Iran. The authors would be grateful all participants in this study.

\section{Authors' contributions}

$\mathrm{RB}, \mathrm{RJ}, \mathrm{FE}, \mathrm{MH}$; Contributed to conception and design. Data collection was performed by RB. Data analysis was done by RB and RJ. The first draft of the manuscript was written by RB and RJ and all authors commented on previous versions of the manuscript. All authors read and approved the final manuscript.

\section{Funding}

Urmia University of Medical Sciences.

\section{Availability of data and materials}

The dataset supporting the conclusions of this article is included within the article.

\section{Ethics approval and consent to participate}

This research was approved by the Ethics Committee of Urmia University of Medical Sciences under code (IR.UMSU.REC.1396.127) and project NO 01-332786. Participants signed a research consent form.

\section{Consent for publication}

Not applicable.

\section{Competing interests}

The authors declare that they have no competing interests.

\section{Author details}

${ }^{1}$ Department of Midwifery, Reproductive Health Research Center, School of Nursing and Midwifery, Urmia University of Medical Sciences, Urmia, Iran. ${ }^{2}$ Department of Midwifery, School of Nursing and Midwifery, Community Based Psychiatric Care Research Center, Shiraz University of Medical Sciences, 7193613119 Shiraz, Iran. ${ }^{3}$ Department of Midwifery, School of Nursing and Midwifery, Urmia University of Medical Sciences, Urmia, Iran. ${ }^{4}$ Department of Obstetrics and Gynecology, School of Medicine, Reproductive Health Research Center, Urmia University of Medical Sciences, Urmia, Iran.

Received: 11 October 2020 Accepted: 28 November 2020

Published online: 07 December 2020

References

1. Berek JS. Berek and Novak's gynecology. 16th ed. Philadelphia: Lippincott Williams \& Wilkins; 2019.

2. Ying $L Y, W u L H$, Loke AY. Gender differences in experiences with and adjustments to infertility: a literature review. Int J Nurs Stud. 2015;52(10):1640-52.

3. Tao P, Coates R, Maycock B. Investigating marital relationship in infertility: a systematic review of quantitative studies. J Reprod Infertil. 2012;13(2):71-80.

4. Mascarenhas MN, et al. National, Regional, and global trends in infertility prevalence since 1990: a systematic analysis of 277 health surveys. PLoS Med. 2012;9(12):e1001356.

5. Direkvand Moghadam A, Delpisheh A, Sayehmiri K. The trend of infertility in Iran, an original review and meta-analysis. Nurs Pract Today. 2014;1(1):46-52.

6. Petok WD. Infertility counselling (or the lack thereof) of the forgotten male partner. Fertil Steril. 2015;104(2):260-6.

7. Gourounti K. Psychological stress and adjustment in pregnancy following assisted reproductive technology and spontaneous conception: a systematic review. Women Health. 2016;56(1):98-118. 
8. Ying $L$, et al. The Partnership and Coping Enhancement Programme for couples undergoing in vitrofertilization treatment: the development of a complex intervention in China. J Assist Reprod Genet. 2017;34(1):99-108.

9. Ying L, Wu LH, Loke AY. Gender differences in emotional reactions to in vitro fertilization treatment: a systematic review. J Assist Reprod Genet. 2016;33(2):167-79.

10. Greil AL, Slauson-Blevins K, McQuillan J. The experience of infertility: a review of recent literature. Sociol Health IIIn. 2010;32(1):140-62.

11. Nasrin M, Sarker MNI, Huda N. Determinants of health care seeking behavior of pregnant slums dwellers in Bangladesh. Med Sci. 2019;23(95):35-41.

12. Cameron EE, Sedov ID, Tomfohr-Madsen LM. Prevalence of paternal depression in pregnancy and the postpartum: an updated meta-analysis. J Affect Disord. 2016;206:189-203.

13. Vänskä $M$, et al. Paternal mental health trajectory classes and early fathering experiences: prospective study on a normative and formerly infertile sample. Int J Behav Dev. 2016:41(5):570-80.

14. Roudsari RL, Allan HT. Women's experiences and preferences in relation to infertility counselling: a multifaith dialogue. Int J Fertil Steril. 2011;5(3):158-67.

15. Dooley $\mathrm{M}$, et al. The psychological impact of infertility and fertility treatment on the male partner. Hum Fertil (Camb). 2014;17(3):203-9.

16. Fisher JR, Hammarberg K. Psychological and social aspects of infertility in men: an overview of the evidence and implications for psychologically informed clinical care and future research. Asian J Androl. 2012;14(1):121-9.

17. Ghavi F, et al. Male infertility and its impact on women's sexual behaviors: need attention to psychological problem as a psychological rehabilitation. Iran Rehabil J. 2017;15(2):87-94

18. White A. Men's health in the 21st century. Int J Mens Health. 2006;5:1-17.

19. Madsen SA. Men's special needs and attitudes as patients. J Mens Health Gend. 2007;4:361-2.

20. Bradshaw C, Atkinson S, Doody O. Employing a qualitative description approach in health care research. Glob Qual Nurs Res. 2017:4:1-8.

21. Bayrami $R$, et al. The perceptions of men awaiting the first child following in vitro fertilization: a qualitative study. Hayat. 2018;24(2):111-26.

22. Graneheim UH, Lundman B. Qualitative content analysis in nursing research: Concepts, procedures and measures to achieve trustworthiness. Nurse Educ Today. 2004;24(2):105-12.

23. Burns N, Grove SK. Understanding nursing research: building an evidence-based practice. 6th ed. Maryland Heights: Elsevier/Saunders; 2015.
24. Arya ST, Dibb B. The experience of infertility treatment: the male perspective. Hum Fertil. 2016;19(4):242-8.

25. Masoumi SZ, et al. Prevalence of depression among infertile couples in Iran: a meta-analysis study. Iran J Public Health. 2013;42(5):458-66.

26. Babore $\mathrm{A}$, et al. Male factor infertility and lack of openness about infertility as risk factors for depressive symptoms in males undergoing assisted reproductive technology treatment in Italy. Fertil Steril. 2017;107(4):1041-7.

27. Warchol-Biedermann K. The risk of psychiatric morbidity and course of distress in males undergoing infertility evaluation is affected by their factor of infertility. Am J Mens Health. 2019;13(1):1557988318823904.

28. Gameiro S, Canavarro MC, Boivin J. Patient centred care in infertility health care: direct and indirect associations with wellbeing during treatment. Patient Educ Couns. 2013;93(3):646-54.

29. Gameiro S, et al. ESHRE guideline: routine psychosocial care in infertility and medically assisted reproduction- a guide for fertility staff. Hum Reprod. 2015;30(11):2476-85

30. Borghi $L$, et al. Patient-centered communication, patient satisfaction, and retention in care in assisted reproductive technology visits. J Assist Reprod Genet. 2019:36(6):1135-42.

31. Hossein Rashidi $B$, et al. The utilization of infertility services by infertile couples in Iranian infertility clinics in 2012-2014. IJOGI. 2017;20(2):1-12.

32. Dyer SJ, et al. Catastrophic payment for assisted reproduction techniques with conventional ovarian stimulation in the public health sector of South Africa: frequency and coping strategies. Hum Reprod. 2013;28(10):2755-64.

33. Behboodi-Moghadam Z, et al. Experiences of infertility through the lens of Iranian infertile women: a qualitative study. Jpn J Nurs Sci. 2013;10(1):41-6.

34. Ranjbar $F$, et al. Experience of infertile women seeking assisted pregnancy in Iran: a qualitative study. J Reprod Infertil. 2015:16(4):221-8.

35. Readings J, et al. Secrecy, disclosure and everything in between: decisions of parents of children conceived by donor insemination, egg donation and surrogacy. Reprod Biomed Online. 2011;22(5):485-95.

\section{Publisher's Note}

Springer Nature remains neutral with regard to jurisdictional claims in published maps and institutional affiliations.
Ready to submit your research? Choose BMC and benefit from:

- fast, convenient online submission

- thorough peer review by experienced researchers in your field

- rapid publication on acceptance

- support for research data, including large and complex data types

- gold Open Access which fosters wider collaboration and increased citations

- maximum visibility for your research: over $100 \mathrm{M}$ website views per year

At $\mathrm{BMC}$, research is always in progress.

Learn more biomedcentral.com/submissions 